\title{
Operant aversive control and Pavlovian higher order conditioning
}

\author{
MICHAEL D. ZEILER and STEPHEN C. WILHITE \\ Emory University, Atlanta, Georgia 30322
}

Pigeons pecked a key for food on a multiple schedule, while pecking in one component also produced time-outs intermittently. The time-outs could be avoided by withholding responses appropriately, and they could be escaped either by responding or by not responding (in separate conditions). Partial suppression of responding during the time-out component was evidence for moderate punishment, and every time-out was escaped successfully. The escape behavior transferred to the warning signal signifying when responses would produce the time-out. The transfer occurred even if this behavior during the signal produced the aversive consequence. The result was that avoidance occurred only if the escape response was the omission of pecking. Responding during the signal was determined neither by its consequences nor by species-specific responses to a salient stimulus, but, rather, by the behavior occurring in the aversive environment itself.

The experiment studicd the properties of an enforced vacation from positive reinforcement. Our interest was in whether such a time-out period would simultaneously operate as a punisher, be avoided, and be escaped. Although each of these potential attributes of time-out had been investigated extensively in the past, earlier experiments did not simultaneously analyze these three potential effects of the presumably aversive event.

\section{METHOD}

\section{Subjects}

Four White Carneaux pigeons were maintained at $80 \%$ of their free-feeding weights. All had extensive experience with a variety of schedules of positive reinforcement.

\footnotetext{
Apparatus

The experimental chamber was a standard single-key pigeon unit. The 2 -cm-diam response key was operated by a minimum force of $.19 \mathrm{~N}$. The key could be transilluminated by two red, blue, yellow, or green 1-W lamps. A $5 \times 6 \mathrm{~cm}$ aperture centered $8 \mathrm{~cm}$ below the key provided occasional access to Purina Pigeon Checkers, the birds' standard diet. During the 4-sec feeder cycles, the key was darkened and the aperture was illuminated by a 1-W white lamp. A $1-W$ white houselight mounted in each upper corner of the panel supporting the key and feeder provided dim general illumination at all times, and continuously present white noise masked extraneous sounds.
}

\section{Procedure}

Food was presented for keypecks occurring at irregular intervals ranging between 5 and $560 \mathrm{sec}$ (average $=180 \mathrm{sec}$ ). This variable-interval (VI 3-min) schedule continued while the color illuminating the key alternated between red and blue every $11 \mathrm{~min}$. Each session had an equal number of red and blue

This research was supported by a grant from the National Science Foundation. The second author is now at Oxford University. Reprint requests should be sent to Michael D. Zeiler, Department of Psychology, Emory University, Atlanta, Georgia 30322. periods: All sessions began with red and terminated with the end of the first blue component occurring after 24 food presentations. This multiple-schedule baseline condition continued for 32 sessions.

The conditions in red then were modified so that the first keypeck occurring between Minutes 10 and 11 changed the key color to yellow. During yellow, food was not available (timeout period). The time-out lasted for 1,200 sec, unless the pigeons met an escape requirement. For two birds (P-71 and P-103), escape entailed withholding a peck for a continuous 100-sec period; for the other two, it required 300 (P-113) or 10 (P-131) pecks. When the time-out ended, the next blue component began. The alternation of red and blue components continued as before.

The pigeons could avoid the time-out and go right from red to blue by not pecking the key at all between Minutes 10 and 11 of red. If no response occurred during this period (occasional probes had time-out production entail 5 or 10 pecks in the 1 -min period instead of 1 , but because these variations had no distinctive effects, they will not be considered further), the time-out was cancelled and the next $11 \mathrm{~min}$ of blue began. Three different conditions of signaling time-out availability were studied several times each for five consecutive sessions. In one condition (seven exposures), no signal indicated when responding would produce the time-out. In a second condition (four exposures), the key was green during the avoidance period (beginning with Minute 10 of red and ending either after $11 \mathrm{~min}$ or when the time-out was produced). In a third condition (four exposures), the warning signal was yellow, that is, the same color signifying that the time-out was in effect.

\section{RESULTS}

\section{Punishment}

Punishment was manifested by lowered response rate in red when pecks produced time-outs. Compared with the baseline condition, absolute rate in red decreased for two birds when responses produced time-outs and did not change for the other two. Rate increased in blue for three of the four and did not change for the fourth bird. The inconsistent patterns made conclusions based 
on absolute rate changes ambiguous. However, a measure involving response rate in the first $10 \mathrm{~min}$ of red relative to the first $10 \mathrm{~min}$ of blue showed that responding decreased more during red than during blue for all four birds. In the baseline sessions, two birds (P-71 and $\mathrm{P}$-131) had higher rates to red (the ratio of red to blue rates was more than 1.00), and two (P-103 and P-113) had higher rates to blue (the ratio of red to blue rates was less than 1.00). In each exposure to all of three time-out conditions, the ratio in the last session always decreased for all four birds, with an average decrease of .21. Differences among the three time-out conditions were small and inconsistent. These relative data implied that the time-outs were punishers, although they did not separate the potential contributions of direct punishment and behavioral contrast to the decrease in red-blue ratios.

\section{Escape}

All of the birds escaped from every time-out. The only exception was that P-131 never escaped in the very first exposure to time-out (the warning signal was yellow). Reliable escape showed that the time-outs were aversive events in that their termination was negatively reinforcing.

\section{Avoidance}

The punishing state that pigeons would work to remove could be avoided altogether by not pecking during Minutes 10-11 of red. No subject ever avoided in the absence of a warning signal, P-113 never avoided under any condition, and P-131 avoided only in the first condition with the yellow warning signal. In contrast, as shown in Figure 1, P-71 and P-103 avoided time-outs in every condition involving warning signals.

The frequency of avoidance by P-71 and P-103 with the yellow signal (yellow also was the time-out stimulus) remained fairly constant in the four exposures, ranging between $70 \%$ and $95 \%$. Such stability did not occur with the green signal. Instead, the frequency of avoidance increased with each successive exposure, as shown by both the individual and combined data in Figure 1. The curves for the green warning signal resembled familiar learning curves, with conditioning becoming more firmly established with successive exposures. The curves for the yellow signal are indicative of asymptotic anticipatory responding under a procedure in which a stimulus controlling not responding occurred only when the prior signal occasioned a response.

Avoidance entailed $60 \mathrm{sec}$ without responses, and hence, food could not be obtained during that period if the time-out was to be avoided. The birds had no way of keeping food continuously available. However, the pigeons could minimize the time without food by avoiding only if the time-out period was longer than $60 \mathrm{sec}$ and by not avoiding otherwise. This did not occur. Although by avoiding frequently, P-71 and

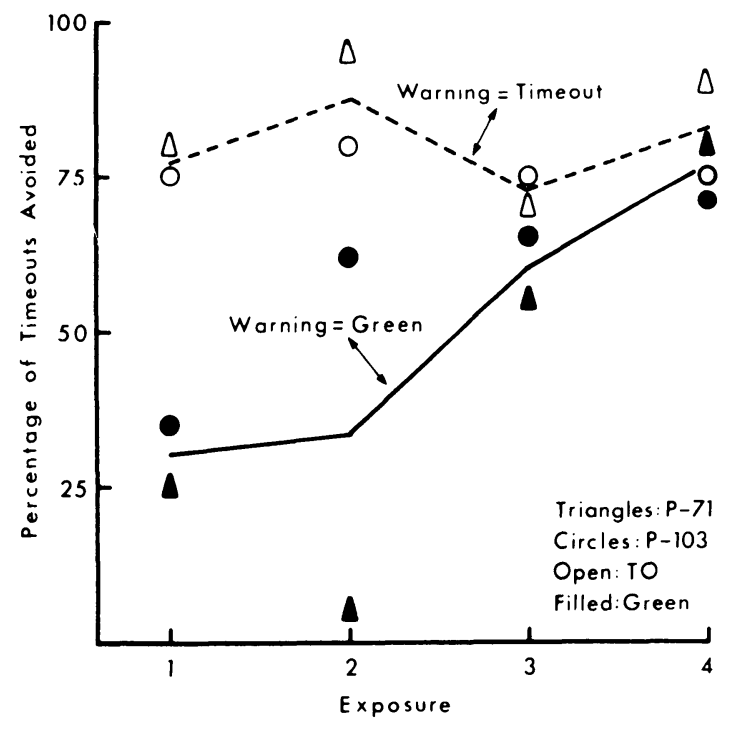

Figure 1. Time-outs avoided in each exposure to the conditions involving warning signals. The solid line shows the averaged data for the filled points (green warning signal); the dashed line shows the averaged data for the unfilled points (yellow warning signal). The triangles and circles show the data for each bird separately, with filled points for the green warning-signal condition and open points for the yellow warning signal. Escape from the time-outs required a continuous $100-\mathrm{sec}$ pause.

P-103 obtained $60 \mathrm{sec}$ without food in exchange for a minimum 100-sec time-out, P-113 did not avoid even though it took over $500 \mathrm{sec}$ to escape from each timeout. In addition, after the various conditions requiring a 100 -sec pause to terminate the time-out, the escape requirement for P-71 and $\mathrm{P}-103$ was changed so that they had to emit 30 pecks to end the time-out. Within two sessions, responding developed during the timeout, and avoidance frequency dropped to $10 \%$. Yet time-out duration averaged $98 \mathrm{sec}$ and was never less than $75 \mathrm{sec}$. In short, avoidance and nonavoidance did not represent choices of the alternative that minimized time without food availability.

Warning signal performance corresponded with that during the time-out itself. When the birds did not respond at all during the time-out, as occurred either when escape entailed a 100 -sec pause or in the first time-out condition for P-131, they often did not respond during the warning signal and thereby avoided. When they did respond during the time-out, as occurred when escape required pecking, they also responded during the signal and thereby failed to avoid.

The importance of behavior during the time-out in determining behavior during the warning signal was revealed further when the escape requirement was changed for P-113 and P-131. For P-113 escape now required not responding for $60 \mathrm{sec}$, but the bird always continued to peck at the beginning of each time-out period, and time to escape averaged $117 \mathrm{sec}$. This bird also pecked as soon as the warning signal appeared and 
consequently never avoided. For P-131, the number of responses to escape was increased progressively to 1,000 , at which point responding during the time-out stopped completely. Up to the 1,000-response requirement, responding continued and no time-outs were avoided; after it, the bird avoided $60 \%$ of the time-outs. Once again, behavior during the warning signal mirrored that during the time-out.

\section{DISCUSSION}

Response-produced time-outs simultaneously generated moderate punishment and strong escape, but only. under specific conditions produced avoidance. Avoidance depended on the consequences of the correspondence between escape and avoidance responses.

A previous experiment on intermittent production of timeouts indicated that time-outs were not effective punishers (Azrin \& Holz, 1966). Responding was maintained by a VI schedule of food presentation, while the first response after $1 \mathrm{~min}$ produced a 60 -sec time-out. Cumulative records showed no rate changes with and without the time-out schedule. Absolute rates did not change enough to be clearly manifested in the present study either, nor were there changes in the way responses were distributed in time, nor were the rate changes that did occur systematic enough to justify concluding that punishment did occur. The conclusion that punishment did indeed occur stemmed from the ratio of rates in the two components, a measure that may have compensated for overall changes in the tendency to respond or, in any event, highlighted the comparison of rates in the time-out and non-time-out components. A parallel (but incomplete) experiment used a simple VI schedule with and without time-outs rather than the multiple schedule of the present study, but it also reimposed baseline conditions several times. Typically, original rates were not recovered when baseline was reinstated; instead, the new baseline rates usually were higher than the originals. The changes in baseline resembled those occurring during the blue (no timeout) component of the present multiple schedule. These results once again imply behavioral contrast, yet the source of the contrast must have been the occurrence of time-outs and the consequent differential punishment.

The most uniform performance was the consistent escape from time-out. The birds clearly discriminated the requirement: They paused if that was necessary and pecked if that ended the time-out (until the peck requirement became excessive). At the same time, the pigeons showed no sign of sensitivity to what was necessary to avoid time-outs. Instead, the warning signal elicited the escape behavior, even though such behavior produced the state of affairs that the birds then would work to terminate. The escape response was conditioned to the warning signal even when it precluded avoidance.

At one time, avoidance behavior was interpreted as transfer of a learned escape response to a stimulus signaling when responding could avoid the impending aversive event (see Herrnstein, 1969, for a review of the history of avoidance conditioning). This interpretation did not survive data showing that any transfer actually involves motivational or emotional reactions and that escape and avoidance motor reactions actually are independent (cf. Mowrer \& Lamoreaux, 1946). The present behavior, therefore, is not a general characteristic of avoidance performance. Nor would it seem to reflect elicitation of a species-specific response by a signal for an impending condition of reinforcement. Ever since the original work on autoshaping (Brown \& Jenkins, 1968; Williams \& Williams, 1969), it has been evident that such signals will elicit pecking in pigeons, even if pecks result in a loss of food. A major difference here was that the signal elicited either pecking or not pecking depending on the specific form of behavior necessary to escape from the time-out. The present results imply a type of Pavlovian higher order conditioning rather than any form of autoshaping. Stimulus generalization is not a plausible alternative explanation given the large amount of data showing that pigeons readily discriminate between green and yellow, Rashotte, Griffin, and Sisk's (1977) finding that pecking transferred to a signal even when the signal and the signaled events involved different sensory modalities, and the fact that avoidance during the warning signal took some time to develop. The latter would seem to be particularly compelling. Stimulus generalization normally is maximal with the initial presentation of a novel stimulus and then declines, but now the similar responses were less prevalent in early exposures to the warning signal and then increased. The stimuli acquired their equivalence in a way that suggested the operation of a conditioning process.

By no accepted definition did the present procedure qualify as Pavlovian conditioning. In a Pavlovian procedure, two stimuli are presented without regard to behavior, but now, presentation of the time-out depended on what the birds did. Yet, the ensuing performance during the warning signal reflected a Pavlovian-like substitution of stimuli. The time-out stimulus was analogous to a Pavlovian conditioned stimulus in that it reliably controlled a learned response, in this case, the escape response. However, this conditioned response was not a replica of any unconditioned reaction. The warning signal was analogous to a second conditioned stimulus, and the discriminated escape behavior moved forward in time to become a higher order conditioned response. The finding parallels higher order Pavlovian conditioning whereby one conditioned stimulus develops the ability to function as an unconditioned stimulus for another conditioned stimulus. A key difference is that now the original stimulusresponse relation originated in operant discrimination training. A related observation was made by Rashotte et al. (1977), who found that pecking was elicited by a stimulus preceding one during which pecks were reinforced by food, and who conducted the controls necessary to conclude that the process was essentially Pavlovian. The present study complemented those results by showing that the higher order conditioned response could be either the emission or the omission of pecks, depending on which was under operant discriminative control.

\section{REFERENCES}

Azrin, N. H., \& Holz, W. C. Punishment. In W. K. Honig (Ed.), Operant behavior: Areas of research and application. New York: Appleton-Century Crofts, 1966.

Brown, P. L., \& Jenkins, H. M. Auto-shaping of the pigeon's keypeck. Journal of the Experimental Analysis of Behavior, 1968, 11, 1-8.

HeRRnsteIN, R. J. Method and theory in the study of avoidance. Psychological Review, 1969, 76, 49-69.

MoWrer, O. H., \& LAMOREAUx, R. R. Fear as an intervening variable in avoidance conditioning. Journal of Comparative and Physiological Psychology, 1946, 39, 29-50.

Rashotte, M. E., Griffin, R. W., \& Sisk, C. L. Second-order conditioning of the pigeon's keypeck. Animal Learning \& Behavior, 1977, 5, 25-38.

Williams, D. R., \& Williams, H. Automaintenance in the pigeon: Sustained pecking despite contingent non-reinforcement. Journal of the Experimental Analysis of Behavior, 1969 , 12, 511-520.

(Received for publication October 11, 1978.) 